\title{
Retinoblastoma treatment: impact of the glycolytic inhibitor 2-deoxy-d-glucose on molecular genomics expression in $\mathrm{LH}_{\mathrm{BETA}} \mathrm{T}_{\mathrm{AG}}$ retinal tumors
}

This article was published in the following Dove Press journal:

Clinical Ophthalmology

27 May 2012

Number of times this article has been viewed

\author{
Yolanda Piña' \\ Samuel K Houston' \\ Timothy G Murray' \\ Tulay Koru-Sengul ${ }^{2,3}$ \\ Christina Decatur ${ }^{1}$ \\ William K Scott ${ }^{4}$ \\ Lubov Nathanson ${ }^{4}$ \\ Jennifer Clarke ${ }^{2}$ \\ Theodore J Lampidis ${ }^{5}$ \\ 'Bascom Palmer Eye Institute, \\ ${ }^{2}$ Department of Epidemiology \\ and Public Health, ${ }^{3}$ Sylvester \\ Comprehensive Cancer Center, \\ ${ }^{4}$ Department of Molecular Genomics, \\ ${ }^{5}$ Department of Cell Biology and \\ Anatomy, University of Miami Miller \\ School of Medicine, Miami, FL, USA
}

Correspondence:Timothy G Murray Bascom Palmer Eye Institute, PO Box 016880 , Miami, FL 33I0I, USA

Tel + I 3053266166

Fax +I 305326 6I47

Email tmurray@med.miami.edu
Purpose: The purpose of this study was to evaluate the effect of 2-deoxy-D-glucose (2-DG) on the spatial distribution of the genetic expression of key elements involved in angiogenesis, hypoxia, cellular metabolism, and apoptosis in $\mathrm{LH}_{\mathrm{BETA}} \mathrm{T}_{\mathrm{AG}}$ retinal tumors.

Methods: The right eye of each $\mathrm{LH}_{\mathrm{BETA}} \mathrm{T}_{\mathrm{AG}}$ transgenic mouse $(\mathrm{n}=24)$ was treated with either two or six subconjunctival injections of 2-DG $(500 \mathrm{mg} / \mathrm{kg})$ or saline control at 16 weeks of age. A gene expression array analysis was performed on five different intratumoral regions (apex, center, base, anterior-lateral, and posterior-lateral) using Affymetrix GeneChip Mouse Gene 1.0 ST arrays. To test for treatment effects of each probe within each region, a two-way analysis of variance was used. Results: Significant differences between treatment groups (ie, 0, 2, and 6 injections) were found as well as differences among the five retinal tumor regions evaluated $(P<0.01)$. More than 100 genes were observed to be dysregulated by $\geq 2$-fold difference in expression between the three treatment groups, and their dysregulation varied across the five regions assayed. Several genes involved in pathways important for tumor cell growth (ie, angiogenesis, hypoxia, cellular metabolism, and apoptosis) were identified.

Conclusions: 2-DG was found to significantly alter the gene expression in $\mathrm{LH}_{\mathrm{BETA}} \mathrm{T}_{\mathrm{AG}}$ retinal tumor cells according to their location within the tumor as well as the treatment schedule. 2-DG's effects on genetic expression found here correlate with previous reported results on varied processes involved in its in vitro and in vivo activity in inhibiting tumor cell growth.

Keywords: retinoblastoma, hypoxia, genetic expression, glycolytic inhibitor, 2-DG

\section{Introduction}

Retinoblastoma is the most common primary intraocular malignancy in children ${ }^{1,2}$ accounting for up to $4 \%$ of all pediatric malignancies in the United States. ${ }^{3}$ Significant advancements in the treatment of this disease have led to over 95\% long-term survival rates in the United States, and current research focuses on tumor control and globe conservation with preservation of sight. ${ }^{4}$ Nevertheless, it is well known that current treatments for retinoblastoma (ie, chemotherapy and focal therapies) result in significant adverse effects at both the systemic and local levels. ${ }^{4-6}$

Retinoblastoma is produced by a mutation leading to the loss of function in both alleles of the tumor suppressor $R B 1$ gene located on chromosome 13q. This anti-oncogene is known to serve functions implicated in cell contact inhibition, differentiation, transcription, cell cycle regulation, proliferation, and apoptosis. ${ }^{5-8}$ The loss of the RBI gene is known to affect several signal transduction pathways responsible for the functions listed above. Over 1000 genes involved in the PI3K, AKT, mTOR, Arf, MDM2, MDM4, and p53 pathways have been found to be 
dysregulated in retinoblastoma. ${ }^{9,10}$ We have recently reported that genes involved with angiogenesis, hypoxia, and cellular metabolism were found to be heterogeneously altered in different regions of the tumor as well as at different time points of tumor growth in a transgenic animal model for retinoblastoma $\left(\mathrm{LH}_{\mathrm{BETA}} \mathrm{T}_{\mathrm{AG}}\right) \cdot{ }^{11}$

The glycolytic inhibitor 2-deoxy-D-glucose (2-DG) has been shown to target angiogenesis and hypoxia both in vitro and in vivo in the $\mathrm{LH}_{\mathrm{BETA}} \mathrm{T}_{\mathrm{AG}}$ transgenic retinoblastoma model, which correlates with its activity as a metabolic inhibitor affecting both glycosylation and glycolysis. ${ }^{12-16}$ We therefore investigated whether 2-DG affected gene expression involved in these processes as well as possible differential activity according to tumor spatial distribution in our in vivo retinoblastoma model. Since current therapies are associated with significant morbidity and potential mortality, our overall goal is to uncover novel therapeutic modalities that will be beneficial to the treatment of retinoblastoma. ${ }^{17-19}$

\section{Materials and methods}

\section{$\mathrm{LH}_{\text {BETA }} \mathrm{T}_{\text {AG }}$ mouse model for}

\section{retinoblastoma}

The study protocol was approved by the University of Miami Institutional Animal Care and Use Review Board Committee. The $\mathrm{LH}_{\mathrm{BETA}} \mathrm{T}_{\mathrm{AG}}$ transgenic mouse model used in this study has been characterized previously. ${ }^{20}$ This animal model develops bilateral multifocal retinal tumors that are stable and grow at a predictable rate (ie, tumor at 4 weeks is undetectable, at 8 weeks is small, at 12 weeks is medium, and at 16 weeks is large). ${ }^{21}$

\section{2-DG treatment}

The right eye (oculus dexter) of each $\mathrm{LH}_{\mathrm{BETA}} \mathrm{T}_{\mathrm{AG}}$ transgenic mouse $(n=24)$ was treated with either two or six subconjunctival injections of 2-DG $(500 \mathrm{mg} / \mathrm{kg}$ ) or saline (vehicle control) at 16 weeks of age. Eyes were treated biweekly for either 1 (two injections) or 3 weeks (six injections). Mice were euthanized with $\mathrm{CO}_{2}$ fumes, and eyes were enucleated and sectioned at 1 day following the last injection. A molecular genetic array analysis was performed in five different areas of the tumor measuring approximately $3.37 \mathrm{~mm}^{3}$. These areas have been previously characterized. ${ }^{22}$ The intratumoral spatial areas included the following: apex, center, base, anteriorlateral, and posterior-lateral. The areas were microdissected manually using a pair of curved microdissecting iridectomy scissors, microdissecting forceps, an Eppendorf (Eppendorf Research Series 2100 adjustable pipette; Hamburg, Germany), and a dissecting microscope (Olympus SZH10 [40 × HPF]; Tokyo, Japan). At all times, experimental manipulation of the tissue was performed under sterile conditions. All the samples $(n=60)$ were placed in a buffer substance containing lysis solution from an RNAqueous-Micro KIT (Ambion, Applied Biosystems, Foster City, CA) and stored at $-20^{\circ} \mathrm{C}$ until analysis was performed. For the histological examination, eyes $(n=12)$ were enucleated, snap-frozen, and serially sectioned (50 8- $\mu \mathrm{m}$ sections per eye).

\section{Molecular genomic array analysis}

A gene expression array analysis was performed on the five different tumor regions obtained from each oculus dexter eye. Molecular analysis focused on two comparative variables: (1) number of injections (ie, zero versus two versus six injections), and (2) treated versus control animals. We used GeneChip Mouse Gene 1.0 ST (Affymetrix, Santa Clara, CA) arrays. RNA was isolated using an RNAqueous-Micro Kit with DNase treatment according to the manufacturing instructions and additionally purified using RNeasy Micro Kit (Qiagen, Hilden, Germany). Samples were amplified with a NuGEN (San Carlos, CA) WT-Ovation Pico kit, and sense-strand cDNA was created using NuGEN WT-Ovation Exon Module. After fragmentation and labeling of cDNA (using NuGEN FL-Ovation cDNA Biotin Module), samples were hybridized for 16 hours with Affymetrix GeneChip Mouse Gene ST 1.0 arrays and washed using Affymetrix Fluidics Station 450. Arrays were scanned using an Affymetrix GeneChip scanner $30007 \mathrm{G}$.

\section{Statistical methods}

Gene- and probe-level expression measures $\left(\log _{2}\right)$ were generated from the raw data using RMAexpress open-source software (http://rmaexpress.bmbolstad.com). Quality-control plots and summary measures were generated using the opensource R/Bioconductor 2.9.10 (http://www.bioconductor. org). ${ }^{23,24}$ Gene-level measures were analyzed using analysis of variance (ANOVA) models for repeated measures, considering treatment or regional effects, using custom scripts written for SAS (v 9.2; SAS Institute, Cary, NC). Genes with a false discovery rate-adjusted $P$-value $<0.01$ from the ANOVA models and a $\log _{2}$ fold change $>2.0$ were considered to be differentially expressed. This yielded a list of differentially expressed genes for each region; each list was then analyzed using GeneGo (St Joseph, MI) software to determine which gene networks and biological pathways were represented by the genes in each list. 


\section{Results \\ 2-DG induces gene expression according to intratumoral spatial location}

To evaluate the impact of focal delivery of 2-DG on several pathways (ie, angiogenesis, hypoxia, cellular metabolism, and apoptosis), $\mathrm{LH}_{\mathrm{BETA}} \mathrm{T}_{\mathrm{AG}}$ mice were treated with two or six injections of 2-DG. There was no apparent toxicity observed in normal adjacent tissue due to the drug at the doses used in the current study. Significant differences in gene expression between treatment groups (ie, zero, two, and six injections) were observed according to the five spatial regions assayed (false discovery rate-adjusted $P<0.01$, ANOVA). The number of genes with $\geq 2$-fold differences in expression were distributed as follows: 34 in the apical, 36 in the central, 20 in the basal, 135 in the anterior-lateral, and 20 in the posteriorlateral regions of the tumor (Table 1). Overall, these results indicate that 2-DG differentially affects gene expression as a function of its location within the tumor.

\section{2-DG induces dysregulation in networks involving angiogenesis, hypoxia, cellular metabolism, and apoptosis}

The top-1000-scored dysregulated genes following treatment with 2-DG were identified to be associated with 52 networks (interacting DNA-encoded segments that regulate the expression of a particular set of genes) in the different intratumoral regions as follows: 13 at the anterior-lateral, 9 at the posterior-lateral, 8 at the apex, 12 at the center, and 10 at the base. Depending on the region assayed, targeted pathways were found to be differentially involved in the networks. Throughout the tumor, genes involved in networks associated with proliferation, apoptosis, migration, hypoxia, and cellular growth were upregulated (Table 2). In specific areas such as the anterior-lateral margin, key genes involved in metastasis, angiogenesis, and cellular metabolism were downregulated, whereas in the central regions, a gene involved in cellular growth and metabolism was also upregulated.

When evaluating the dysregulated genes by network, we found that genes involved in angiogenesis were primarily dysregulated in the leading edges of the tumor (apical, anteriorlateral, and posterior-lateral) (Table 3). The highest percentage of angiogenic activity was found in the apex (Figure 1). In this region factors including estrogen receptor 1 nuclear (ESR1 nuclear), ubiquitin, jun activation domain-binding protein 1 (JAB1), G-protein alpha-s, and CAPER were upregulated. On the other hand, in the anterior-lateral margin, angiogenesis was inhibited through pathways involving myostatin, cyclin-depen- dent kinase 2 (CDK2), p53, c-Myc, and plasminogen activator inhibitor-1 (PAI1). In the posterior-lateral region, cell proliferation was mediated by c-Myc, which upregulated factors including $\beta,-1,3-\mathrm{N}$-acetylglucosaminyltransferase 1 (B3GNT1), choline/ethanolamine phosphotransferase 1 (CEPT1), poly A tail binding-protein cytoplasmic 1 (PABPC1), myotrophin, and HS1-associated protein X-1 (HAX1) (Table 3). Thus, different genes in the angiogenic network were found to be dysregulated according to their location in the leading edges of the tumor.

Genes stimulated by hypoxia were found to be dysregulated mainly in basal regions of the tumor (Figure 2). Several hypoxia-related genes that encode the transcription factor SMAD5 and several proteins including histone H3, DTX1, ribosomal protein L12 (RPL12), and bone morphogenic protein (BMP) receptor 2 were upregulated. However, genes associated with cellular metabolism and apoptosis were dysregulated in all the different tumor areas analyzed (Table 3 ). The apex showed the highest percentage of dysregulated metabolic genes, which encode factors including the transcription factor SP1 involving $N$-acetylglucosamine (GlcNAc) kinase, dual oxidase 1 (DUOX1), and glucosamine-fructose-6phosphate aminotransferase 1 (GFPT1; Figure 3). On the other hand, the anterior-lateral margin of the tumor showed the highest percentage of dysregulated apoptosis-related factors, including the caspase family (ie, caspase- $2,-3,-7,-8,-9$; Figure 4). Although genes dysregulated by 2-DG are found throughout the tumor, the basal regions presented with the highest percentage of hypoxia-related genes, while the apical and anterior-lateral regions presented with the highest percentage of cellular metabolic and apoptotic-related genes, respectively.

\section{Discussion}

The current study is the first to show that treatment with the glycolytic inhibitor 2-DG is associated with significant spatial changes in the gene expression related to angiogenesis, hypoxia, cellular metabolism, and apoptosis in the $\mathrm{LH}_{\mathrm{BETA}} \mathrm{T}_{\mathrm{AG}}$ retinoblastoma tumor model. In this tumor, 2-DG was previously shown to target intratumoral hypoxic cells in vivo and effectively reduce tumor burden. . $^{12,13,15,16,25}$ During advanced stages of tumor development, low $\mathrm{O}_{2}$ tension conditions increase in regions deficient in nutrients and vasculature. Under these hypoxic conditions, cells adjust their metabolism to rely on glycolysis for adenosine triphosphate (ATP) production and survival. ${ }^{26}$ Houston et al located a number of genes differentially expressed during retinoblastoma tumor 
Table I Genes with $\geq 2$-fold differences in expression between the three treatment groups by intratumoral region. These genes were distributed as follows: 34 in the apical, 36 in the central, 20 in the basal, 135 in the anterior-lateral, and 20 in the posteriorlateral regions of the tumor

\begin{tabular}{|c|c|c|c|c|}
\hline \multirow{2}{*}{$\begin{array}{l}\text { Region } \\
\text { Gene }\end{array}$} & \multicolumn{3}{|c|}{ Treatment } & \multirow[t]{2}{*}{$P$-value } \\
\hline & 6 vs 0 & 6 vs 2 & 2 vs 0 & \\
\hline \multicolumn{5}{|l|}{ Apex } \\
\hline$A L D H 3 A I$ & 2.21 & 2.17 & 0.04 & I.I6E-04 \\
\hline$B \cup B I$ & -1.55 & -2.25 & 0.70 & $7.48 \mathrm{E}-05$ \\
\hline CASC5 & -1.95 & -2.52 & 0.57 & $3.38 \mathrm{E}-05$ \\
\hline CCNBI & -1.47 & -2.12 & 0.65 & 3.09E-05 \\
\hline $\mathrm{CDH} 9$ & -1.39 & -2.20 & 0.81 & I.IIE-05 \\
\hline CENPF & -1.35 & -2.12 & 0.78 & $2.50 \mathrm{E}-05$ \\
\hline CENPH & -1.44 & -2.27 & 0.82 & $9.16 \mathrm{E}-05$ \\
\hline CENPK & -1.13 & -2.46 & 1.34 & 5.65E-05 \\
\hline CRYAA & 2.58 & 3.70 & -1.12 & I.35E-05 \\
\hline CRYBAI & 3.25 & 4.33 & -1.08 & $5.50 \mathrm{E}-05$ \\
\hline CRYBA2 & 1.77 & 2.43 & -0.66 & $3.04 \mathrm{E}-05$ \\
\hline CRYBA4 & 2.12 & 3.18 & -1.07 & $2.59 \mathrm{E}-05$ \\
\hline CRYBB2 & 1.91 & 2.14 & -0.24 & I.70E-06 \\
\hline CRYGB & 1.68 & 3.05 & -1.37 & 3.4IE-05 \\
\hline CRYGC & 1.46 & 2.52 & -1.06 & $5.35 \mathrm{E}-05$ \\
\hline CRYGD & 1.72 & 2.74 & -1.02 & I.04E-04 \\
\hline CRYGS & 3.47 & 4.69 & -1.22 & $7.02 \mathrm{E}-05$ \\
\hline$D C N$ & 2.03 & 1.93 & 0.10 & I.44E-04 \\
\hline EG665955 & -1.77 & -2.24 & 0.48 & $6.56 \mathrm{E}-06$ \\
\hline GENI & -1.14 & -2.11 & 0.97 & $2.76 \mathrm{E}-05$ \\
\hline GPX3 & 2.47 & 1.96 & 0.51 & I.24E-05 \\
\hline HBA-AI & 0.51 & 2.21 & -1.70 & $3.88 \mathrm{E}-10$ \\
\hline HBA-A2 & 0.48 & 2.18 & -1.70 & 5.IIE-I0 \\
\hline HBB-BI & 0.75 & 2.11 & -1.37 & $1.93 \mathrm{E}-09$ \\
\hline$H B B-B I$ & 0.77 & 2.09 & -1.32 & $9.30 \mathrm{E}-10$ \\
\hline KRT5 & 2.40 & 2.00 & 0.40 & $3.04 \mathrm{E}-05$ \\
\hline MASTL & -1.29 & -2.06 & 0.77 & $2.70 \mathrm{E}-05$ \\
\hline MNSI & -2.05 & -2.29 & 0.24 & I.83E-06 \\
\hline NCAPG & -1.38 & -2.37 & 0.99 & 5.73E-05 \\
\hline OPTC & 2.21 & 2.15 & 0.06 & I.03E-05 \\
\hline PBK & $-|.7|$ & -2.14 & 0.44 & $6.05 E-05$ \\
\hline SGOL2 & -1.15 & -2.01 & 0.86 & $2.78 \mathrm{E}-05$ \\
\hline SHCBPI & $-1.4 \mid$ & -2.01 & 0.61 & 4.36E-05 \\
\hline TOP2 A & -1.50 & -2.14 & 0.65 & I.20E-05 \\
\hline \multicolumn{5}{|l|}{ Center } \\
\hline$A P O D$ & 1.31 & -1.08 & 2.39 & 2.79E-05 \\
\hline CALBI & 0.70 & 2.10 & -1.40 & I.44E-06 \\
\hline CENPF & -2.11 & -1.65 & -0.46 & $6.8 \mathrm{IE}-06$ \\
\hline CRYAA & 3.43 & 3.74 & -0.31 & 4.57E-06 \\
\hline CRYBAI & 3.71 & 3.74 & -0.03 & 3.73E-05 \\
\hline CRYBA2 & 2.76 & 2.89 & -0.14 & $5.28 \mathrm{E}-06$ \\
\hline CRYBA4 & 3.40 & 3.17 & 0.23 & I.72E-05 \\
\hline CRYBB2 & 2.54 & 2.31 & 0.23 & I.47E-06 \\
\hline CRYGB & 2.11 & 1.64 & 0.48 & $5.72 \mathrm{E}-05$ \\
\hline CRYGC & $2.7 I$ & 2.22 & 0.49 & 5.19E-05 \\
\hline CRYGD & 2.38 & 1.55 & 0.84 & I.02E-04 \\
\hline CRYGS & 4.46 & 4.20 & 0.26 & 5.93E-05 \\
\hline$D C N$ & 1.79 & -1.37 & 3.16 & I.08E-04 \\
\hline
\end{tabular}

Table I (Continued)

\begin{tabular}{|c|c|c|c|c|}
\hline \multirow{2}{*}{$\begin{array}{l}\text { Region } \\
\text { Gene }\end{array}$} & \multicolumn{3}{|c|}{ Treatment } & \multirow[t]{2}{*}{$\overline{P \text {-value }}$} \\
\hline & 6 vs 0 & 6 vs 2 & 2 vs 0 & \\
\hline$D C T$ & 2.57 & 0.18 & 2.39 & I.02E-05 \\
\hline DPT & 1.79 & -0.28 & 2.07 & $6.26 \mathrm{E}-04$ \\
\hline EG665955 & -1.97 & -2.03 & 0.06 & 2.IIE-05 \\
\hline EIF2S3Y & 2.24 & 2.06 & 0.18 & I.96E-03 \\
\hline$E M C N$ & 0.59 & -1.45 & 2.04 & $6.76 \mathrm{E}-07$ \\
\hline FABP7 & 1.36 & 2.02 & -0.67 & $2.21 \mathrm{E}-06$ \\
\hline GM9912 & 0.32 & -1.80 & 2.12 & I.33E-05 \\
\hline GPX3 & 2.21 & 1.16 & 1.05 & $2.18 \mathrm{E}-05$ \\
\hline LGSN & 2.14 & 1.69 & 0.45 & $4.38 \mathrm{E}-06$ \\
\hline MGP & 0.47 & -1.64 & 2.11 & $3.08 \mathrm{E}-08$ \\
\hline MLANA & 1.76 & -0.67 & 2.43 & I.55E-05 \\
\hline OPNIMW & 0.28 & 2.12 & -1.84 & $2.03 \mathrm{E}-06$ \\
\hline OPNISW & 2.21 & 2.17 & 0.04 & $4.08 \mathrm{E}-05$ \\
\hline PBK & -2.03 & -1.78 & -0.25 & I.02E-05 \\
\hline PENK & 2.01 & 1.88 & 0.13 & $3.04 \mathrm{E}-05$ \\
\hline PTPN3 & -1.56 & -2.34 & 0.78 & I.03E-05 \\
\hline PTPN3 & -1.30 & -2.19 & 0.89 & I.24E-06 \\
\hline $\mathrm{RDH} / 2$ & 1.14 & 2.03 & -0.89 & $6.19 \mathrm{E}-06$ \\
\hline SI & 1.37 & -0.69 & 2.06 & I.26E-05 \\
\hline TOP2A & -2.26 & -2.11 & -0.15 & I.34E-05 \\
\hline TYRPI & 1.60 & -0.88 & 2.47 & I.73E-05 \\
\hline XIST & -2.00 & -2.28 & 0.28 & $6.65 \mathrm{E}-04$ \\
\hline$X L R$ & -2.19 & -0.24 & -1.95 & I.78E-05 \\
\hline \multicolumn{5}{|l|}{ Base } \\
\hline ALDH3AI & 2.20 & 2.01 & 0.19 & I.66E-04 \\
\hline B4302 I ICO8RI & -2.04 & -1.32 & -0.72 & I.07E-07 \\
\hline CRYAA & 3.09 & 3.78 & -0.69 & $6.39 \mathrm{E}-07$ \\
\hline CRYBAI & 3.11 & 4.61 & -1.50 & $5.18 \mathrm{E}-06$ \\
\hline CRYBA2 & 1.84 & 2.20 & -0.36 & $8.35 \mathrm{E}-08$ \\
\hline CRYBA4 & 2.70 & 3.33 & -0.63 & $4.02 \mathrm{E}-06$ \\
\hline CRYBB2 & 1.92 & 2.45 & -0.53 & I.2IE-07 \\
\hline CRYGB & 1.33 & 2.33 & -1.01 & $5.58 \mathrm{E}-05$ \\
\hline CRYGC & 1.54 & 2.05 & -0.51 & I.I5E-04 \\
\hline CRYGD & 1.89 & 2.30 & -0.41 & $3.32 \mathrm{E}-04$ \\
\hline CRYGS & 3.50 & 4.88 & -1.38 & $6.50 \mathrm{E}-06$ \\
\hline DSC3 & 2.09 & 1.72 & 0.37 & $9.69 \mathrm{E}-04$ \\
\hline DSGIA & 2.13 & 1.72 & 0.41 & $3.98 \mathrm{E}-04$ \\
\hline EG665955 & -1.87 & -2.19 & 0.32 & I.67E-05 \\
\hline FGFBPI & 2.11 & 1.90 & 0.22 & I.66E-04 \\
\hline GM9912 & -1.11 & -2.23 & 1.12 & $5.20 \mathrm{E}-06$ \\
\hline KRT4 & 2.26 & 1.19 & 1.07 & $3.96 \mathrm{E}-04$ \\
\hline LYPD2 & 1.53 & 2.06 & -0.54 & $2.33 \mathrm{E}-05$ \\
\hline TACSTD2 & 2.10 & 1.53 & 0.57 & $3.64 \mathrm{E}-04$ \\
\hline XIST & -1.95 & -2.08 & 0.12 & $6.78 \mathrm{E}-04$ \\
\hline \multicolumn{5}{|c|}{ Anterior-lateral } \\
\hline I600029D2IRI & -1.64 & 0.99 & -2.63 & $3.52 \mathrm{E}-04$ \\
\hline $22 I 0023 G 05 R I$ & -1.50 & 0.60 & -2.10 & $6.52 \mathrm{E}-04$ \\
\hline $26|0528 \mathrm{~A} I| R I$ & -1.34 & 0.68 & -2.02 & $3.54 \mathrm{E}-04$ \\
\hline 943003 I JI6RI & 1.35 & -0.80 & 2.14 & $5.42 \mathrm{E}-05$ \\
\hline $9930032022 R I$ & -1.24 & 0.77 & -2.01 & $4.50 \mathrm{E}-03$ \\
\hline$A B C D 2$ & 0.99 & -1.14 & 2.13 & $9.36 \mathrm{E}-05$ \\
\hline$A D H I$ & -1.88 & $0.4 \mathrm{I}$ & -2.29 & I.76E-03 \\
\hline$A D H 6 B$ & -1.87 & 0.30 & -2.17 & $2.06 \mathrm{E}-03$ \\
\hline
\end{tabular}


Table I (Continued)

\begin{tabular}{|c|c|c|c|c|}
\hline \multirow{2}{*}{$\begin{array}{l}\text { Region } \\
\text { Gene }\end{array}$} & \multicolumn{3}{|c|}{ Treatment } & \multirow[t]{2}{*}{$P$-value } \\
\hline & 6 vs 0 & 6 vs 2 & 2 vs 0 & \\
\hline Al504432 & 1.08 & $-1.2 \mid$ & 2.29 & $9.48 \mathrm{E}-05$ \\
\hline AIMI & -1.35 & 0.77 & -2.12 & I.32E-03 \\
\hline ALDH3AI & -1.69 & 0.71 & -2.40 & $3.4 \mathrm{IE}-03$ \\
\hline ANXA8 & -1.48 & 0.86 & -2.34 & 4.63E-03 \\
\hline$A P I S 2$ & 1.06 & -1.05 & 2.10 & 3.06E-05 \\
\hline ARHGEF3 & -1.62 & 0.44 & -2.06 & I.43E-04 \\
\hline$B A / 3$ & 1.25 & -0.76 & 2.01 & 2.43E-05 \\
\hline BC030476 & -1.13 & 0.89 & -2.02 & I.40E-04 \\
\hline$B C 100530$ & -1.63 & 0.77 & -2.40 & $2.12 \mathrm{E}-03$ \\
\hline$B \cup B I$ & -1.08 & -2.09 & 1.01 & I.70E-04 \\
\hline $\mathrm{CI} 3002 \mathrm{II} 20 \mathrm{RI}$ & -2.62 & 0.31 & -2.93 & 7. $10 \mathrm{E}-05$ \\
\hline CABP5 & 1.86 & -0.25 & 2.12 & $4.08 \mathrm{E}-05$ \\
\hline CALML3 & -1.46 & 1.11 & -2.57 & I. $14 \mathrm{E}-03$ \\
\hline CAPNS2 & -1.26 & 1.14 & -2.40 & 7.23E-04 \\
\hline CARIO & 1.82 & -0.51 & 2.33 & $2.78 \mathrm{E}-05$ \\
\hline CAR3 & -1.73 & 0.52 & -2.26 & 7.I5E-05 \\
\hline CCNBI & -1.45 & -2.22 & 0.77 & I.35E-04 \\
\hline CCNBI & -1.31 & -2.16 & 0.85 & I.I5E-04 \\
\hline CCNBI & -1.29 & -2.10 & 0.81 & I.09E-04 \\
\hline $\mathrm{CDH} 9$ & 1.25 & -1.63 & 2.89 & $2.00 \mathrm{E}-04$ \\
\hline CENPH & -2.01 & -2.03 & 0.02 & I.8IE-04 \\
\hline CENPK & -1.20 & -2.23 & 1.02 & I.53E-04 \\
\hline CES3 & -1.36 & 0.67 & -2.03 & I.19E-03 \\
\hline CHD7 & 1.24 & -0.99 & 2.23 & $3.52 \mathrm{E}-05$ \\
\hline CRYAA & 2.41 & 2.56 & -0.15 & I.I7E-04 \\
\hline CRYBAI & 4.10 & 3.35 & 0.75 & $8.32 \mathrm{E}-05$ \\
\hline CRYBA4 & 2.28 & 2.27 & 0.01 & I.93E-04 \\
\hline CRYGB & 2.61 & 1.76 & 0.84 & $9.15 \mathrm{E}-04$ \\
\hline CRYGC & 2.77 & 1.72 & 1.05 & I.33E-03 \\
\hline CRYGD & 2.90 & 1.97 & 0.93 & I. $24 \mathrm{E}-03$ \\
\hline CRYGS & 4.04 & 3.44 & 0.60 & 5.19E-04 \\
\hline DSC2 & -1.19 & 0.82 & -2.01 & I.92E-03 \\
\hline DSC3 & -1.28 & 0.90 & -2.18 & $9.42 \mathrm{E}-03$ \\
\hline DSGIA & -1.47 & 0.69 & -2.15 & $6.27 \mathrm{E}-03$ \\
\hline DSG3 & -1.56 & 1.14 & -2.69 & $3.54 \mathrm{E}-03$ \\
\hline$D S P$ & -1.27 & 0.89 & -2.15 & $4.08 \mathrm{E}-03$ \\
\hline EG665955 & -2.09 & -2.43 & 0.34 & 2. $18 \mathrm{E}-05$ \\
\hline ELF3 & -1.13 & 0.95 & -2.08 & $5.64 \mathrm{E}-04$ \\
\hline EPHA7 & 1.23 & -0.96 & 2.18 & 7.87E-05 \\
\hline ESRPI & -1.27 & 0.94 & -2.20 & I.67E-03 \\
\hline FAM $38 B$ & -1.72 & 0.54 & -2.26 & I.62E-04 \\
\hline FAT3 & I.7I & -0.51 & 2.21 & 7.09E-05 \\
\hline FAT3 & 1.87 & -0.22 & 2.09 & 3.73E-05 \\
\hline FSTL5 & 1.45 & -0.62 & 2.06 & $4.38 \mathrm{E}-05$ \\
\hline GABRAI & 1.83 & -0.24 & 2.07 & $3.54 \mathrm{E}-05$ \\
\hline GABRB2 & 1.81 & -0.80 & 2.61 & 3.9IE-05 \\
\hline GABRB2 & 0.98 & -1.19 & 2.17 & I.16E-04 \\
\hline GABRG2 & 1.84 & -0.79 & 2.63 & $8.36 \mathrm{E}-05$ \\
\hline GMI0639 & -1.64 & 0.53 & -2.16 & I.38E-03 \\
\hline GM4792 & 1.31 & -0.86 & 2.17 & $2.38 \mathrm{E}-06$ \\
\hline GM9573 & -1.35 & 0.80 & -2.15 & I.2IE-03 \\
\hline GM99/2 & 0.92 & -1.26 & 2.18 & 7.4IE-05 \\
\hline GRIA2 & 1.58 & -0.48 & 2.06 & I.76E-05 \\
\hline
\end{tabular}

Table I (Continued)

\begin{tabular}{|c|c|c|c|c|}
\hline \multirow{2}{*}{$\begin{array}{l}\text { Region } \\
\text { Gene }\end{array}$} & \multicolumn{3}{|c|}{ Treatment } & \multirow[t]{2}{*}{$P$-value } \\
\hline & 6 vs 0 & 6 vs 2 & 2 vs 0 & \\
\hline GSTAI & -2.01 & 0.61 & -2.61 & $2.16 \mathrm{E}-03$ \\
\hline GSTAI & -1.96 & 0.59 & -2.56 & I.97E-03 \\
\hline GSTA2 & -1.63 & 0.57 & -2.21 & I.24E-03 \\
\hline GSTOI & -0.90 & 1.42 & -2.32 & $3.05 \mathrm{E}-04$ \\
\hline$H M M R$ & -1.13 & -2.14 & 1.01 & I.3IE-04 \\
\hline IMPG2 & 1.28 & -0.73 & 2.01 & $4.98 \mathrm{E}-05$ \\
\hline KIFII & -1.32 & -2.05 & 0.73 & I. $42 \mathrm{E}-04$ \\
\hline KLF4 & -1.59 & 0.44 & -2.03 & I.82E-04 \\
\hline KRTI2 & -1.38 & 0.88 & -2.26 & I.06E-03 \\
\hline KRT5 & -1.46 & 0.96 & -2.42 & I.44E-03 \\
\hline KRT6A & $-1.4 \mid$ & 0.81 & -2.22 & I.24E-03 \\
\hline KRT6B & -1.39 & 0.72 & -2.11 & $2.35 \mathrm{E}-03$ \\
\hline LCE3A & -3.08 & 0.28 & -3.36 & $9.18 \mathrm{E}-05$ \\
\hline LCN2 & 0.94 & -1.72 & 2.66 & 4.79E-05 \\
\hline LGSN & 2.27 & 1.50 & 0.77 & 2.IIE-04 \\
\hline LIPM & -1.02 & 1.03 & -2.05 & $6.76 \mathrm{E}-04$ \\
\hline LMO7 & -1.37 & 0.85 & -2.22 & $8.55 \mathrm{E}-04$ \\
\hline LY6G6C & -2.21 & 0.30 & $-2.5 I$ & 7.04E-04 \\
\hline LYPD2 & -1.90 & 0.56 & -2.46 & 7.03E-04 \\
\hline LYPD3 & -1.49 & 0.74 & -2.23 & $2.70 \mathrm{E}-04$ \\
\hline MAL & -1.42 & 0.62 & -2.05 & 4.93E-04 \\
\hline MAL2 & -1.13 & 1.05 & -2.18 & I.32E-03 \\
\hline MDGA2 & 1.67 & -0.60 & 2.27 & $6.23 \mathrm{E}-05$ \\
\hline MDGA2 & 1.66 & -0.60 & 2.26 & $3.80 \mathrm{E}-05$ \\
\hline MUC4 & -1.06 & 0.98 & -2.04 & $6.62 \mathrm{E}-04$ \\
\hline NCAPG & -1.15 & -2.12 & 0.97 & I.I3E-04 \\
\hline NCAPG2 & -0.94 & -2.03 & 1.09 & 8.69E-05 \\
\hline NDC80 & $-|.3|$ & -2.13 & 0.81 & I.27E-04 \\
\hline NEURODI & 1.95 & -0.39 & 2.35 & $4.83 \mathrm{E}-05$ \\
\hline NEUROD 4 & 1.91 & -0.48 & 2.38 & $3.3 \mathrm{IE}-05$ \\
\hline NOVAI & 0.92 & -1.21 & 2.14 & $8.29 \mathrm{E}-05$ \\
\hline NRXN3 & 1.57 & -0.43 & 2.00 & I.69E-05 \\
\hline NUDTIO & 1.08 & -0.94 & 2.02 & I.02E-04 \\
\hline NUF2 & -0.95 & -2.14 & 1.19 & I.26E-04 \\
\hline OPNISW & 1.03 & 2.02 & -1.00 & 4.39E-04 \\
\hline OTOR & 1.60 & -0.96 & 2.56 & I.06E-04 \\
\hline PBK & -0.85 & -2.12 & 1.26 & I.86E-04 \\
\hline PCDHB3 & 0.94 & -1.12 & 2.05 & I.IIE-04 \\
\hline POFIB & -1.45 & 0.78 & -2.23 & I.70E-03 \\
\hline PPIL5 & -1.10 & -2.22 & 1.12 & 7.78E-05 \\
\hline PROXI & 1.85 & -0.25 & 2.09 & $5.46 \mathrm{E}-05$ \\
\hline PSCA & -1.30 & 1.44 & -2.74 & $3.60 \mathrm{E}-04$ \\
\hline PTPN3 & -2.06 & -0.94 & -1.12 & I.I5E-05 \\
\hline RHOX4A & -1.82 & 0.56 & -2.38 & $3.95 \mathrm{E}-04$ \\
\hline RHOX4B & -1.79 & 0.59 & -2.38 & 4.22E-04 \\
\hline RHOX $4 B$ & -1.82 & 0.55 & -2.37 & $6.46 \mathrm{E}-04$ \\
\hline RHOX4C & -1.80 & 0.59 & -2.38 & $3.68 \mathrm{E}-04$ \\
\hline RHOX4E & -1.80 & 0.54 & -2.35 & $3.80 \mathrm{E}-04$ \\
\hline RHOX4F & -1.77 & 0.61 & -2.38 & 3.77E-04 \\
\hline RHOX4G & -1.61 & 0.47 & -2.08 & $2.34 \mathrm{E}-04$ \\
\hline RPE65 & -0.67 & 1.59 & -2.25 & 3.38E-04 \\
\hline SIOOA/4 & -1.57 & 0.51 & -2.08 & I.22E-03 \\
\hline
\end{tabular}


Table I (Continued)

\begin{tabular}{|c|c|c|c|c|}
\hline \multirow{2}{*}{$\begin{array}{l}\text { Region } \\
\text { Gene }\end{array}$} & \multicolumn{3}{|c|}{ Treatment } & \multirow[t]{2}{*}{$P$-value } \\
\hline & 6 vs 0 & 6 vs 2 & 2 vs 0 & \\
\hline SCG3 & 2.28 & -0.40 & 2.67 & $7.12 \mathrm{E}-05$ \\
\hline SCIN & -1.46 & 0.61 & -2.07 & I.57E-03 \\
\hline SCN2AI & 0.81 & $-|.3|$ & 2.13 & $3.52 \mathrm{E}-05$ \\
\hline SERPINA3N & 2.17 & 0.40 & 1.77 & 7.59E-05 \\
\hline SERPINB5 & -1.55 & 0.64 & -2.20 & $6.66 \mathrm{E}-03$ \\
\hline SLC28A3 & -1.30 & 0.73 & -2.03 & 7.65E-04 \\
\hline SLC6AI 4 & -1.92 & 0.75 & -2.67 & $3.48 \mathrm{E}-03$ \\
\hline SLURPI & $-1.6 \mid$ & 0.45 & -2.05 & I.0IE-03 \\
\hline SNORD6I & 1.02 & -1.16 & 2.18 & 6.07E-05 \\
\hline SPINK5 & -1.55 & 0.74 & -2.29 & I.43E-03 \\
\hline SULF2 & 1.02 & -1.09 & 2.11 & $3.43 \mathrm{E}-05$ \\
\hline TDRKH & 1.21 & -0.87 & 2.08 & $2.45 \mathrm{E}-05$ \\
\hline TMPRSSIIB & -1.28 & 1.11 & -2.39 & $5.02 \mathrm{E}-03$ \\
\hline TMPRSSIIE & -1.29 & 0.76 & -2.05 & 2. $12 \mathrm{E}-03$ \\
\hline TMSBI5BI-TMS & 1.03 & -1.20 & 2.23 & 7.27E-05 \\
\hline TNS4 & -1.44 & 0.70 & -2.14 & 2.86E-04 \\
\hline TRIM29 & -1.31 & 0.82 & -2.13 & I.86E-03 \\
\hline TUBB3 & 1.52 & -0.63 & 2.15 & I.9IE-05 \\
\hline UPKIB & -1.95 & 0.77 & -2.72 & $3.16 \mathrm{E}-03$ \\
\hline XIST & -0.72 & -2.38 & 1.66 & 2.47E-03 \\
\hline$X L R 4 C$ & -1.93 & 0.52 & -2.45 & I.47E-03 \\
\hline ZFP804A & 1.81 & -0.22 & 2.03 & I.08E-05 \\
\hline \multicolumn{5}{|c|}{ Posterior-lateral } \\
\hline 4833423E24RI & -2.37 & -1.19 & -1.18 & 4.47E-04 \\
\hline APBH & -2.69 & $-|.5|$ & -1.18 & I.07E-04 \\
\hline CRYAA & 2.02 & 3.47 & -1.45 & $6.76 \mathrm{E}-05$ \\
\hline CRYBAI & 1.39 & 4.68 & -3.29 & $5.00 \mathrm{E}-05$ \\
\hline CRYBA2 & 1.46 & 2.65 & -1.19 & 5.87E-05 \\
\hline CRYBA4 & 1.50 & 3.22 & -1.72 & 8.15E-05 \\
\hline CRYBB2 & 1.20 & 2.34 & -1.14 & 7.I3E-06 \\
\hline CRYGB & 1.07 & 2.17 & -1.10 & 3.63E-04 \\
\hline CRYGD & 0.68 & 2.35 & -1.67 & $8.32 \mathrm{E}-04$ \\
\hline CRYGS & 1.76 & 4.06 & -2.30 & 5. $17 \mathrm{E}-04$ \\
\hline GP2 & -2.97 & -1.90 & -1.07 & I.35E-03 \\
\hline LCE3A & -2.07 & -0.30 & -1.77 & I.49E-08 \\
\hline LGII & -2.13 & -1.34 & -0.78 & 4. $16 \mathrm{E}-05$ \\
\hline SNORDII6 & 2.12 & 0.55 & 1.57 & 3.6IE-06 \\
\hline SNORDII 6 & 2.07 & 0.63 & $\mathrm{I} .44$ & $3.47 \mathrm{E}-06$ \\
\hline SNORD6I & 0.67 & -1.60 & 2.27 & $6.99 \mathrm{E}-06$ \\
\hline SNORD 82 & 1.78 & -0.54 & 2.33 & I.70E-06 \\
\hline STFA3 & -2.20 & -1.36 & -0.84 & 8.75E-04 \\
\hline TRDN & 1.27 & -0.87 & 2.14 & I.67E-04 \\
\hline XIST & $-|.8|$ & -2.08 & 0.26 & $4.82 \mathrm{E}-04$ \\
\hline
\end{tabular}

Notes: All values are fold change $=\log _{2}$ (I st value/2nd value); all $P$ values $<0.00$ I, two-way analysis of variance. In bold are pairwise comparisons in which the gene has demonstrated a $\geq 2.5$-fold difference in expression between the treatment groups.

development, with dysregulated genes involved in angiogenesis, hypoxia, and cellular metabolism. ${ }^{11}$ Upregulated gene expression related to angiogenesis and metabolism was predominantly found in the leading edges of the tumors, whereas those involved in hypoxia were found in the base. ${ }^{11}$ Immunohistochemistry studies in vivo have shown parallel results, displaying a higher concentration of neovessels in the leading edges of the tumor, mature blood vessels in the center, ${ }^{27}$ and hypoxia in the base. ${ }^{12}$

In the present study, 2-DG treatment caused a heterogeneous alteration in the expression of genes associated with angiogenesis, hypoxia, metabolism, and apoptosis. ${ }^{11}$ The use of 2-DG treatment orchestrated changes in gene expression mediating apoptosis in the five different intratumoral areas analyzed. The anterior-lateral margin of the tumor, characterized with the highest percentage of apoptosis and cell death, presented an upregulation of the cysteine proteases, the caspase- $2,-3,-7,-8$, and -9 supergene family (Figure 4).

Genes related to hypoxia were found to be upregulated only in the base of the tumors following treatment (Figure 2). In this region, the transcription factor SMAD5 and several proteins, including histone H3, DTX1, RPL12, and BMP receptor 2, were overproduced. Histone $\mathrm{H} 3$ was previously shown to be stimulated in response to hypoxia during tumor development in this tumor region. ${ }^{11}$ SMAD5 is physically associated with HIF and hypoxia and is the main promoter of angiogenesis, VEGF, and TFG-beta2 gene expression. ${ }^{28-30}$ In the current study, histone $\mathrm{H} 3$ and SMAD5 were controlled by HIF $1 \alpha$. HIF $1 \alpha$ usually increases in response to hypoxia and stimulates cellular metabolism to allow the cancer cell to rely on glycolysis..$^{15,26,31-35}$ In these retinoblastoma tumors, HIF $1 \alpha$ was not found to be dysregulated either during tumor development ${ }^{11}$ or following $2-\mathrm{DG}$ treatment. However, the current data indicates that HIF $1 \alpha$ remains activated despite the use of 2-DG, suggesting that this transcription factor is not entirely degraded, as typically occurs in the presence of $\mathrm{O}_{2}$, and that $\mathrm{O}_{2}$ levels remain low in the base of these tumors despite the elimination of hypoxic cells. DTX1 (a hypoxiainduced Notch1 target-binding protein), RPL12, and BMP receptor 2 were also upregulated in the base of these tumors. In previous studies, decreased stability of DTX1 has been associated with low HIF $1 \alpha$ levels. ${ }^{36}$ In the current study, the presence of HIF1 $\alpha$ stimulated NOTCH1, which in turn increased the production of DTX1 and RPL12. The role of BMP signaling and tumor cell proliferation is not clear in the literature. While BMP has been shown to inhibit the proliferation of prostate tumor cells, ${ }^{37}$ it has also been shown to stimulate the growth of other tumor cells such as human colon carcinomas. ${ }^{38}$ In the current study, BMP receptor 2 signaling was found to be associated with SMAD proteins, stimulating the upregulation of SMAD5 and thus of angiogenesis in this retinoblastoma model, as was previously seen in other cancer cells. $^{37}$ 
Table 2 Genes involved in angiogenesis, hypoxia, cellular metabolism, and apoptosis with $\geq 2$-fold difference in expression between the three treatment groups

\begin{tabular}{|c|c|c|c|c|c|c|}
\hline \multirow[t]{2}{*}{ Gene } & \multirow{2}{*}{ Function } & \multirow{2}{*}{ Expression } & \multirow{2}{*}{$\begin{array}{l}\text { Intratumoral } \\
\text { region }\end{array}$} & \multicolumn{3}{|c|}{ Treatment } \\
\hline & & & & 6 vs 0 & 6 vs 2 & 2 vs 0 \\
\hline \multirow[t]{5}{*}{ CRYGS } & Cell proliferation, apoptosis, and migration & Upregulated & Posterior-lateral & 1.7646 & 4.0608 & -2.2962 \\
\hline & & Upregulated & Anterior-lateral & 4.0379 & 3.4377 & 0.6002 \\
\hline & & Upregulated & Center & 4.4602 & 4.2007 & 0.2595 \\
\hline & & Upregulated & Apex & 3.4701 & 4.6914 & -1.2213 \\
\hline & & Upregulated & Base & 3.503 & 4.8839 & -1.3809 \\
\hline \multirow[t]{5}{*}{ CRYAA } & Apoptosis, hypoxia, and cell growth & Upregulated & Posterior-lateral & 2.0195 & 3.4697 & -1.4502 \\
\hline & & Upregulated & Anterior-lateral & 2.4138 & 2.5635 & -0.1497 \\
\hline & & Upregulated & Center & 3.4345 & 3.7442 & -0.3097 \\
\hline & & Upregulated & Apex & 2.5789 & 3.697 & -1.1181 \\
\hline & & Upregulated & Base & 3.089 & 3.78 & -0.691 \\
\hline PSCA & Metastasis & Downregulated & Anterior-lateral & -1.3016 & 1.4423 & -2.7439 \\
\hline CALML3 & Angiogenesis & Downregulated & Anterior-lateral & -1.4569 & 1.1096 & -2.5665 \\
\hline GSTA I & Cellular metabolism & Downregulated & Anterior-lateral & -1.9646 & 0.5932 & -2.5578 \\
\hline DCT & Cell growth and cellular metabolism & Upregulated & Center & 2.5688 & 0.1812 & 2.3876 \\
\hline
\end{tabular}

Notes: All values are fold change $=\log _{2}$ (Ist value/2nd value); all $P$ values $<0.00$, two-way analysis of variance. In bold are pairwise comparisons in which the gene has demonstrated $\mathrm{a} \geq 2.5$-fold difference in expression between the treatment groups.

The shift to anaerobic metabolism under hypoxia causes a synchronized and intricate alteration in gene expression with the ultimate goal of supplying the cell with enough resources to rely on glycolysis for survival. Glycolytic inhibitors may not only reduce tumor burden by affecting glycolysis but also by working as anti-angiogenic agents. Previous studies have shown that endothelial cell expression of glucose transporters and uptake are upregulated by angiogenic growth factors as well as by hypoxia. ${ }^{39-42}$ Also, 2-DG has the potential to decrease blood-vessel density in vivo in the $\mathrm{LH}_{\mathrm{BETA}} \mathrm{T}_{\mathrm{AG}}$ transgenic animal model of retinoblastoma and to inhibit endothelial cell growth in vitro. ${ }^{43}$ As a biological indicator for proliferation and tumor growth, ${ }^{44} 47$ angiogenesis has stimulated an increase in research focus on anti-angiogenic therapies for cancer over the past decade. ${ }^{48-52}$ Nonetheless, previous studies suggest that anti-angiogenic therapy is ineffective at causing tumor regression, ${ }^{53}$ mainly on large tumors that are predominantly occupied by the matured, pericyte-surrounded blood vessels. ${ }^{54} \mathrm{~A}$ combination therapy that targets both pericytes and angiogenesis has been shown to cause a higher percentage of tumor burden and vasculature decrease. ${ }^{53} \mathrm{Also}$, the low $\mathrm{O}_{2}$-sensitive mTOR that stimulates cellular metabolism and angiogenesis through the upregulation of $\mathrm{HIF}^{26}$ was found to decrease tumor burden by both decreasing intratumoral hypoxia and mature blood vessels. ${ }^{55}$

In the current study, 2-DG altered angiogenic gene expression in the leading edges of the tumor (Table 3), with the apex presenting the most active angiogenic activity (Figure 1). We have established that tumor development in the $\mathrm{LH}_{\mathrm{BETA}} \mathrm{T}_{\mathrm{AG}}$ retinoblastoma tumor has an ongoing angiogenesis predominantly present in these same tumor areas (ie, leading edges). ${ }^{11,27}$ The current study suggests that 2-DG further alters angiogenesis. In the apical tumor, the downstream activation of transcription factor ESR1 was associated with the upregulation of gene expression of CAPER and JAB1. ESR1 was previously found to be regulated by retinoblastoma-associated proteins $\mathrm{RbAp} 48$ and $\mathrm{RbAp} 46$, which are involved in chromatin remodeling, histone deacetylation, and transcription repression. ${ }^{56}$ CAPER typically interacts with ESR1 and ESR2 to work as a coactivator of transcription, while JAB1stimulates the breakdown of the cyclin-dependent kinase inhibitor p27Kip1 and regulates HIF by cleaving ubiquitin-like proteins. ${ }^{57}$ Ubiquitin, which is required for the destruction of HIF in the presence of $\mathrm{O}_{2}$, was also found to be upregulated following 2-DG treatment in the current study; as well as the GTPase G-protein- $\alpha-s$, known to stimulate the production of cAMP from ATP, thus activating the cAMP-dependent pathway and the phosphorylation of a number of downstream targets through protein kinase $\mathrm{A}$.

Because anaerobic glycolysis is a less resourceful method to generate ATP than oxidative phosphorylation, the metabolism of cells under hypoxia slows down dramatically due to increasing metabolic demands. However, since different levels of $\mathrm{O}_{2}$ tension naturally develop in these hypoxic regions, some cells rely more than others on glycolysis for survival, thus responding differently to glycolytic inhibition. In the current study, 2-DG caused alterations in the genetic expression involved in metabolism, with the apex showing the highest per- 
Table 3 Factors dysregulated in different networks associated with the angiogenic, hypoxic, cellular metabolic, and apoptotic pathways

\begin{tabular}{|c|c|c|c|c|c|c|}
\hline Area & Key network objects & GO Processes & $\begin{array}{l}\text { Total } \\
\text { nodes }\end{array}$ & $\begin{array}{l}\text { Root } \\
\text { nodes }\end{array}$ & Pathways & $P$ value \\
\hline \multicolumn{7}{|l|}{ Angiogenesis } \\
\hline Apex & $\begin{array}{l}\text { ESRI (nuclear), ubiquitin, } \\
\text { JABI, G-protein alpha-s, } \\
\text { CAPER }\end{array}$ & $\begin{array}{l}\text { Regulation of cell proliferation ( } 60.0 \%) \text {, response } \\
\text { to endogenous stimulus }(50.0 \%) \text {, response to hormone } \\
\text { stimulus ( } 48.0 \%) \text {, response to chemical stimulus } \\
(70.0 \%) \text {, response to organic substance }(56.0 \%)\end{array}$ & 50 & 8 & 94 & $1.93 \mathrm{e}-07$ \\
\hline Anterior-lateral & $\begin{array}{l}\text { P53, CDK2, c-Myc, } \\
\text { SPI, PAII }\end{array}$ & $\begin{array}{l}\text { Response to electrical stimulus ( } 5.7 \%) \text {, regulation } \\
\text { of transcription ( } 40.0 \%) \text {, regulation of metanephric } \\
\text { cap mesenchymal cell proliferation ( } 2.9 \%) \text {, negative } \\
\text { regulation of skeletal muscle tissue growth ( } 2.9 \%) \text {, } \\
\text { I0-formyltetrahydrofolate biosynthetic process }(2.9 \%)\end{array}$ & 50 & 50 & 3 & $4.42 \mathrm{e}-34$ \\
\hline Posterior-lateral & $\begin{array}{l}\text { B3GNI, CEPTI, } \\
\text { PABPCI, HAXI, } \\
\text { myotrophin }\end{array}$ & $\begin{array}{l}\text { Regulation of metanephric cap mesenchymal cell } \\
\text { proliferation }(6.2 \%) \text {, positive regulation of metanephric } \\
\text { cap mesenchymal cell proliferation }(6.2 \%) \text {, neuron } \\
\text { differentiation }(25.0 \%) \text {, putrescine biosynthetic } \\
\text { process }(6.2 \%) \text {, putrescine metabolic process }(6.2 \%)\end{array}$ & 50 & 8 & 0 & $1.25 \mathrm{e}-12$ \\
\hline \multicolumn{7}{|l|}{ Hypoxia } \\
\hline Base & $\begin{array}{l}\text { SMAD5, DTXI, BMP } \\
\text { receptor 2, histone } \\
\text { H3, RPLI2 }\end{array}$ & $\begin{array}{l}\text { Organ morphogenesis }(57.1 \%) \text {, anatomical structure } \\
\text { morphogenesis }(61.9 \%) \text {, transmembrane receptor } \\
\text { protein serine/threonine kinase signaling pathway } \\
\text { ( } 28.6 \%) \text {, BMP signaling pathway ( } 21.4 \%) \text {, regulation } \\
\text { of cell differentiation }(45.2 \%)\end{array}$ & 50 & 15 & 33 & 2. $18 \mathrm{e}-17$ \\
\hline \multicolumn{7}{|c|}{ Cellular metabolism } \\
\hline Apex & $\begin{array}{l}\text { GIcNAc kinase, } \\
\text { DUOXI, GFPTI, } \\
\text { RPOM, WDRI3 }\end{array}$ & $\begin{array}{l}\text { Translational elongation }(23.3 \%) \text {, translation }(30.0 \%) \text {, } \\
\text { cellular metabolic process }(86.7 \%) \text {, biosynthetic } \\
\text { process }(63.3 \%) \text {, metabolic process }(90.0 \%)\end{array}$ & 50 & 22 & 0 & $1.23 \mathrm{e}-33$ \\
\hline Center & $\begin{array}{l}\text { PDE2A, PRKAR2A, } \\
\text { ZNF28I, BRD7, } \\
\text { UFDI }\end{array}$ & $\begin{array}{l}\text { Primary metabolic process }(85.7 \%) \text {, polyamine } \\
\text { biosynthetic process }(7.1 \%) \text {, cellular metabolic } \\
\text { process }(82.1 \%) \text {, positive regulation of Wnt receptor } \\
\text { signaling pathway }(7.1 \%) \text {, metabolic process }(85.7 \%)\end{array}$ & 50 & 12 & 0 & $2.44 \mathrm{e}-14$ \\
\hline Base & $\begin{array}{l}\text { GSK3 beta, NCOA3 } \\
\text { (PCIP/SRC3), P38 alpha } \\
\text { (MAPKI4), N-CoR, } \\
\text { CAPER }\end{array}$ & $\begin{array}{l}\text { Tube development ( } 25.0 \%) \text {, positive regulation } \\
\text { of macromolecule metabolic process }(35.4 \%) \text {, } \\
\text { positive regulation of cellular metabolic process }(35.4 \%) \text {, } \\
\text { positive regulation of metabolic process }(35.4 \%) \text {, } \\
\text { tissue development }(31.2 \%)\end{array}$ & 50 & 32 & 19 & $2.85 e-49$ \\
\hline Posterior-lateral & $\begin{array}{l}\text { PCBP-I, MTB-Zf, elF4E, } \\
\text { ERK5 (MAPK7), } \\
\text { RanGAPI }\end{array}$ & $\begin{array}{l}\text { Organelle organization ( } 40.4 \%) \text {, cell cycle }(29.8 \%) \text {, cellular } \\
\text { component organization }(51.1 \%) \text {, regulation of cell cycle } \\
\text { (19.1\%), regulation of cellular metabolic process }(53.2 \%)\end{array}$ & 50 & 20 & 0 & $3.22 \mathrm{e}-27$ \\
\hline \multicolumn{7}{|l|}{ Apoptosis } \\
\hline Apex & $\begin{array}{l}\text { MNKI, La protein, } \\
\text { RecQ5, CD47, } \\
\text { RING-box protein I }\end{array}$ & $\begin{array}{l}\text { DNA fragmentation involved in apoptosis }(9.3 \%) \text {, } \\
\text { cell structure disassembly during apoptosis }(9.3 \%) \text {, } \\
\text { apoptotic nuclear changes }(9.3 \%) \text {, DNA catabolic process, } \\
\text { endonucleolytic }(9.3 \%) \text {, induction of apoptosis ( } 18.6 \%)\end{array}$ & 50 & 20 & 0 & $2.72 \mathrm{e}-26$ \\
\hline Center & $\begin{array}{l}\text { FAKI, GSK3 beta, } \\
\text { CCRI0, tubulin } \\
\text { (in microtubules), } \\
\text { tenascin-C }\end{array}$ & $\begin{array}{l}\text { Regulation of apoptosis }(60.0 \%) \text {, regulation } \\
\text { of programmed cell death }(60.0 \%) \text {, regulation of cell } \\
\text { death }(60.0 \%) \text {, multicellular organismal development } \\
(84.0 \%) \text {, developmental process }(86.0 \%)\end{array}$ & 50 & 5 & 64 & $3.87 e-04$ \\
\hline Base & $\begin{array}{l}\text { NUDI2, ATP6M, } \\
\text { PDCD5, PSMDI, } \\
\text { HISTIH3D }\end{array}$ & $\begin{array}{l}\text { Apoptosis }(27.3 \%) \text {, programmed cell death }(27.3 \%) \text {, } \\
\text { induction of apoptosis }(21.2 \%) \text {, induction } \\
\text { of programmed cell death }(21.2 \%) \text {, cell death }(27.3 \%)\end{array}$ & 50 & 18 & 0 & $2.53 e-23$ \\
\hline Anterior-lateral & $\begin{array}{l}\text { Caspase-3, caspase-7, } \\
\text { caspase-8, caspase- } 9 \text {, } \\
\text { caspase-2 }\end{array}$ & $\begin{array}{l}\text { Apoptosis }(75.0 \%) \text {, programmed cell death }(75.0 \%) \text {, } \\
\text { cell death }(75.0 \%) \text {, death }(75.0 \%) \text {, induction of } \\
\text { apoptosis }(54.2 \%)\end{array}$ & 50 & 42 & 964 & $7.9|\mathrm{e}-2|$ \\
\hline Posterior-lateral & $\begin{array}{l}\text { c-Cbl, PGE2RI, } \\
\text { FCGRT, IDE, } \\
\text { GALNT2 }\end{array}$ & $\begin{array}{l}\text { Intracellular signaling cascade ( } 39.5 \%) \text {, regulation } \\
\text { of localization }(30.2 \%) \text {, regulation of apoptosis }(32.6 \%) \text {, } \\
\text { regulation of programmed cell death }(32.6 \%) \text {, } \\
\text { regulation of cell death }(32.6 \%)\end{array}$ & 50 & 11 & 2 & $2.7 \mathrm{Ie}-12$ \\
\hline
\end{tabular}

Note: $P<0.001$, two-way analysis of variance.

Abbreviation: GO, gene ontology. 


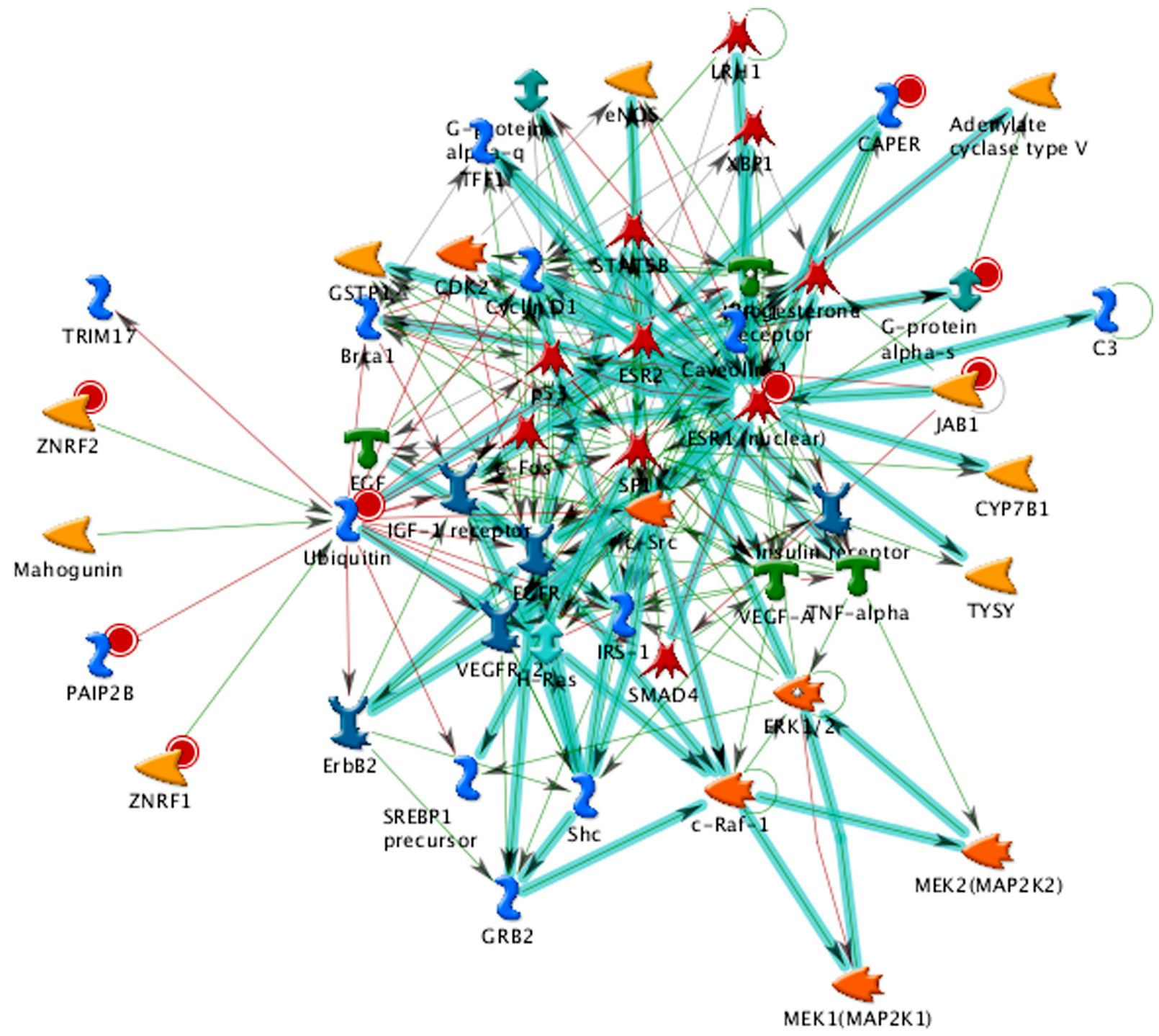

Figure I The apex of the $\mathrm{LH}_{\mathrm{BETA}} T_{\mathrm{AG}}$ retinal tumors presented with the highest percentage of angiogenesis. Several factors were found dysregulated following treatment with 2-DG. Key objects include ESRI nuclear, ubiquitin, JABI, and CAPER. Red dots mean that the factor was upregulated.

centage of cellular metabolic process upregulation (Table 3). Key enzymes mediated by the transcription factor SP1 in the promotion of cellular metabolism in the apex involved GlcNAc kinase, DUOX1, and GFPT1 (Figure 3). Whereas GlcNAc kinase has a low affinity for glucose, ${ }^{58}$ this enzyme may produce high-energy intermediates for glycolysis as a stress response to cellular metabolism by increasing the conversion of glucosamine-6-phosphate to fructose-6-phosphate. ${ }^{59}$ Sugar analogs other than 2-DG (eg, mannoheptulose and GlcNAc kinase) were previously found to inhibit glucokinase and glucose uptake and decrease growth rate in a number of tumor cell lines; ${ }^{60}$ therefore, 2-DG may have a dual action on metabolism by increasing GlcNAc kinase to produce highenergy glycolytic intermediates and by inhibiting GlcNAc, which is phosphorylated by GlcNAc kinase in the regulation of transcription, translation, cell signaling, and stress response to carbohydrate metabolism. ${ }^{61,62}$ On the other hand, DUOX1 catalyzes the regulated formation of reactive oxygen species and is associated with arginase 2 and eNOS-related genes (p21, Akt1, HIF-1, VEGF, and CAV1) in a number of solid tumors. ${ }^{63,64}$ Additionally, involved in the hexosamine pathway and flux of glucose, GFPT1 was found to be a predictor for overall survival in patients with pancreatic cancer. ${ }^{65}$

We have previously shown that there is a temporaldependent heterogeneous distribution of angiogenesis, blood-vessel maturation, and hypoxia in $\mathrm{LH}_{\mathrm{BETA}} \mathrm{T}_{\mathrm{AG}}$ retinal tumors. ${ }^{12,13,27,66}$ We further elucidated temporal and regional differences in the genetic expression of factors associated with these pathways. ${ }^{67}$ In the current study, we showed a heterogeneous alteration in gene expression in angio- 


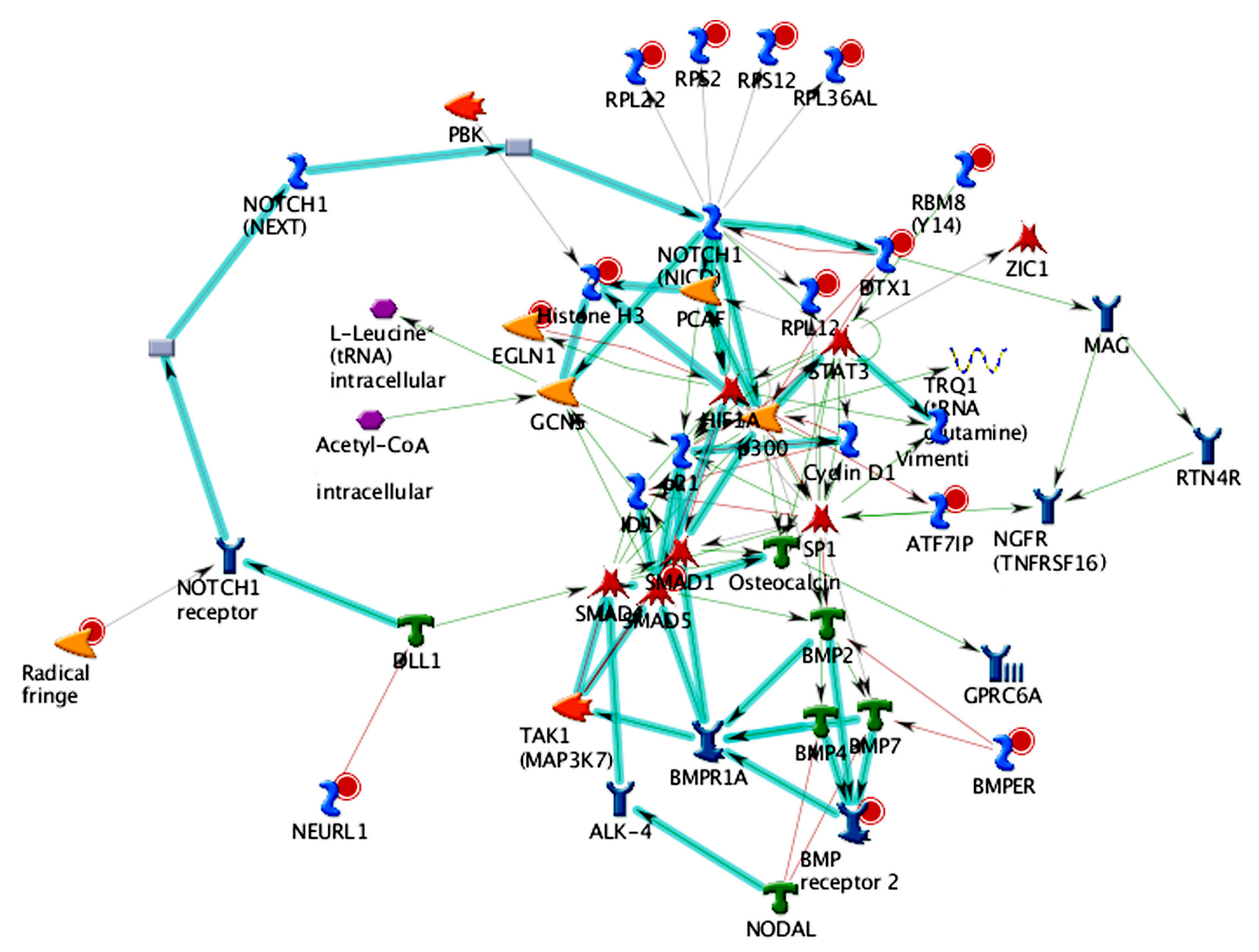

Figure 2 The base of the $\mathrm{LH}_{\mathrm{BETA}} \mathrm{T}_{\mathrm{AG}}$ retinal tumors presented with the upregulation of hypoxia-related genes. Hypoxia was altered following 2-DG treatment in the base of the tumors only. Key upregulated hypoxia-related factors include SMAD5, histone H3, DTXI, RPLI2, and BMP receptor 2. Red dots mean that the factor was upregulated.

genesis, hypoxia, metabolism, and apoptosis following treatment with 2-DG. This heterogeneity may have an important impact on treatment effect, as different populations of tumor cells express genetic differences, therefore resulting in varying responses to treatments. As a result, an understanding of this heterogeneous microenvironment during tumor development is essential to best select and make use of combination treatments for retinoblastoma. For instance, a combination therapy of chemotherapy with a glycolytic inhibitor and an anti-angiogenic agent would most effectively target hypoxic regions on basal regions of the tumor during later stages of the disease and angiogenic new vasculature on the peripheral regions of the tumor during early stages of the disease. Thus an understanding of the dynamic aspect of tumor development and timing of gene expression is needed to optimally time treatments to maximize efficacy.

The evaluation of gene expression of tumors following adjuvant treatment to target specific cell pathways may prove important in order to optimize a synergistic effect on tumor-burden reduction with minimal side effects. Additionally, gene expression following treatments allows for a greater understanding of the mechanisms involved for a particular agent, as well as for the identification of escape mechanisms that cells may utilize to gain resistance. Future studies are needed to determine differential gene expression and the effect on the tumor microenvironment following adjuvant therapies and in combination with standard therapies for cancer. Additional functional studies as well as correlation with human retinoblastoma tumors are also needed to define the pathophysiology and unique genotypic fingerprints of retinoblastoma tumors. We anticipate the development of novel therapeutics to target key pathways in tumor growth and development, thus serving as adjuvant agents to current standard treatments.

Limitations of the current study include the small sample size of 12 mice eyes for both treatment and control. Additionally, our study investigates the effects of time and location in the $\mathrm{LH}_{\text {BETA }} \mathrm{T}_{A G}$ murine model of retinoblastoma, 


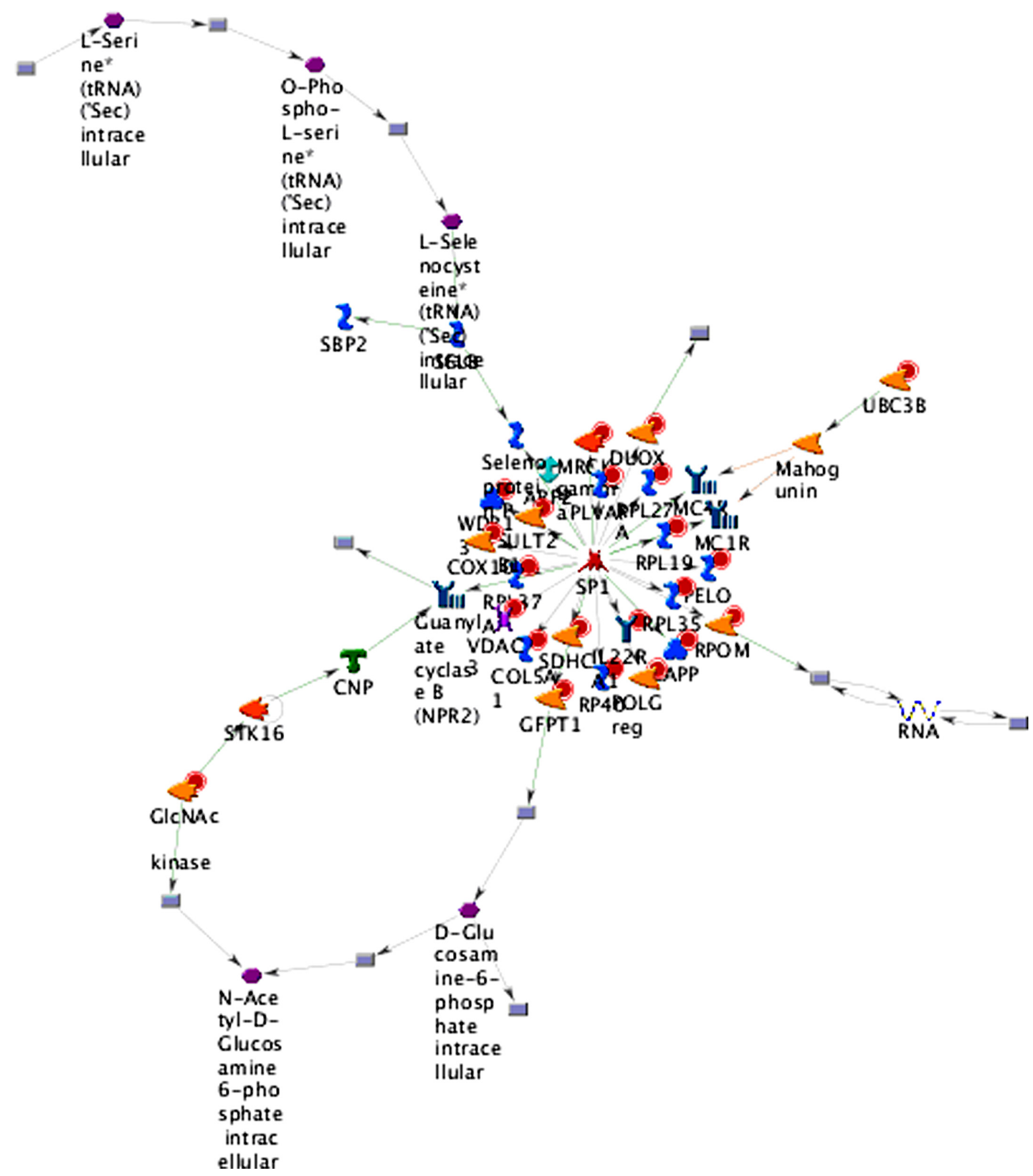

Figure 3 The apex of the $\mathrm{LH}_{\text {BETA }} \mathrm{T}_{\mathrm{AG}}$ retinal tumors presented with the highest percentage of cellular metabolism. Key factors mediating metabolism in the apex were stimulated by transcription factor SPI following 2-DG treatment. These objects include GIcNAc kinase, DUOXI, and GFPTI. Red dots mean that the factor was up regulated.

which has been shown to share many similarities with human retinoblastoma, but the correlation in gene expression between human and mouse tumors has not been fully determined. As a result, prior to relating the current findings to human retinoblastoma, further functional studies are needed with transgenic retinoblastoma tumors and human retinoblastoma cell lines.
In conclusion, the current study builds on the prior findings that retinoblastoma tumors in the murine model demonstrate differential gene expression that is regionally and temporally related. This study indicates that the unique gene expression profiles of treated tumors have significant regional differences, as well as differences dependent on treatment schedule. 


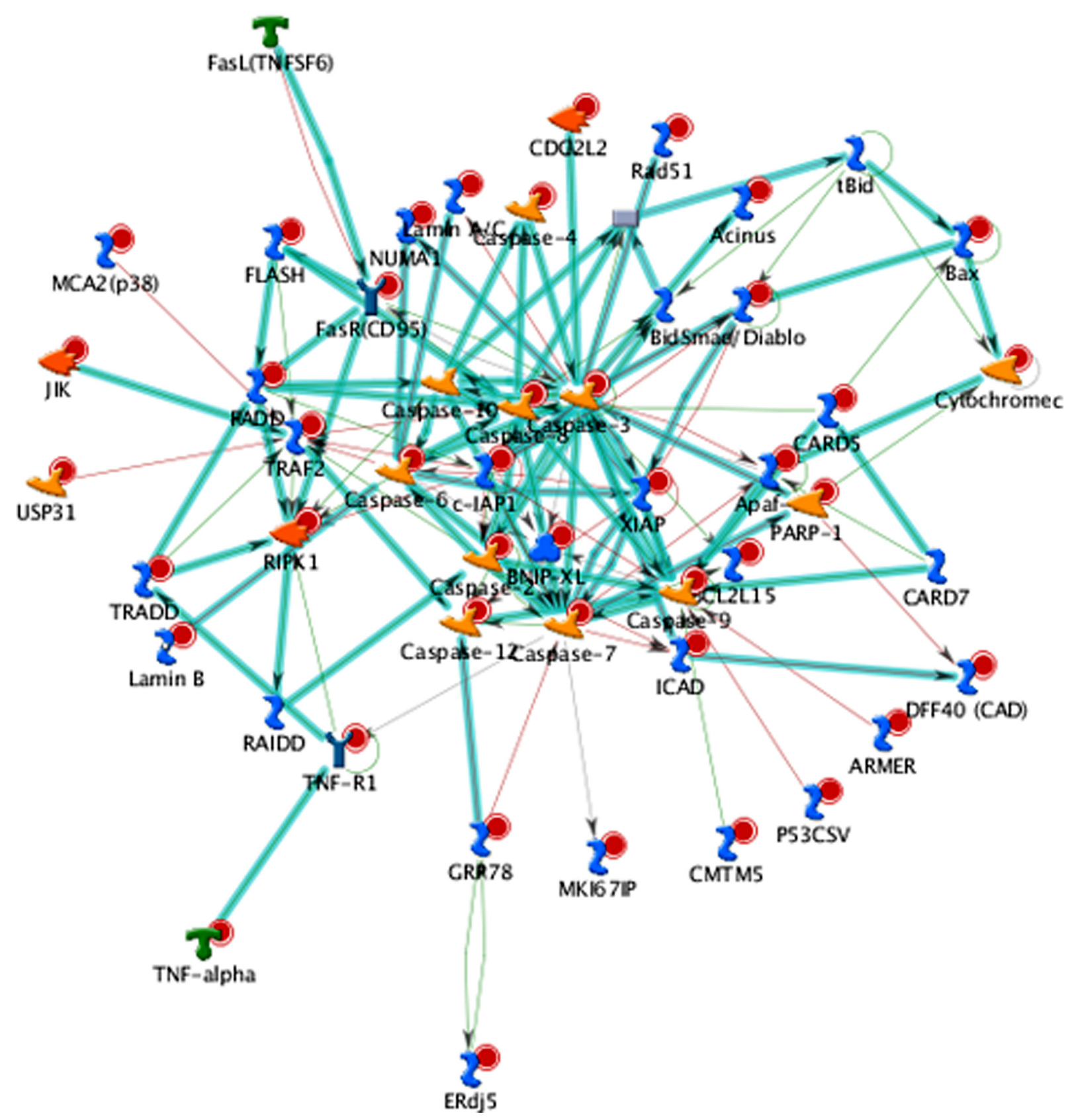

Figure 4 The anterior-lateral margin of the $\mathrm{LH}_{\mathrm{BETA}} \mathrm{T}_{\mathrm{AG}}$ retinal tumors presented with the highest percentage of apoptosis and cell death. Key factors involved in the upregulation of apoptosis in these tumors include caspase-2, $-3,-7,-8$, and -9 . Red dots mean that the factor was up regulated.

\section{Acknowledgments}

Supported by NIH center grant R01 EY013629, R01 EY12651, and P30 EY014801; by the American Cancer Society, Sylvester Comprehensive Cancer Center; and by an unrestricted grant to the University of Miami from Research to Prevent Blindness, Inc. L Nathanson, T Koru-Sengul, and J Clarke had full access to all the data in the study and take responsibility for the integrity of the data and the accuracy of the data analysis.

\section{Disclosure}

The authors report no conflicts of interest in this work.

\section{References}

1. Pendergrass TW, Davis S. Incidence of retinoblastoma in the United States. Arch Ophthalmol. 1980;98:1204-1210.

2. Tamboli A, Podgor MJ, Horm JW. The incidence of retinoblastoma in the United States: 1974 through 1985. Arch Ophthalmol. 1990;108:128-132.

3. Abramson DH. Retinoblastoma in the 20th century: past success and future challenges. The Weisenfeld lecture. Invest Ophthalmol Vis Sci. 2005;46:2683-2691. 
4. Laurie NA, Schin-Shih C, Dyer MA. Targeting MDM2 and MDMX in retinoblastoma. Curr Cancer Drug Targets. 2007;7:689-695.

5. DeGregori J, Johnson DG. Distinct and overlapping roles for E2F family members in transcription, proliferation and apoptosis. Curr Mol Med. 2006;6:739-748.

6. Liu Y, Dean DC. Tumor initiation via loss of cell contact inhibition versus Ras mutation: do all roads lead to EMT? Cell Cycle. 2010;9: 897-900.

7. Dunn JM, Phillips RA, Becker AJ, Gallie BL. Identification of germline and somatic mutations affecting the retinoblastoma gene. Science. 1988;241:1797-1800.

8. Classon M, Harlow E. The retinoblastoma tumour suppressor in development and cancer. Nat Rev Cancer. 2002;2:910-917.

9. Chakraborty S, Khare S, Dorairaj SK, Prabhakaran VC, Prakash DR, Kumar A. Identification of genes associated with tumorigenesis of retinoblastoma by microarray analysis. Genomics. 2007;90: 344-353

10. Laurie NA, Donovan SL, Shih CS, et al. Inactivation of the $\mathrm{p} 53$ pathway in retinoblastoma. Nature. 2006;444:61-66.

11. Houston SK, Pina Y, Clarke J, et al. Regional and temporal differences in gene expression of $\mathrm{LH}(\mathrm{BETA}) \mathrm{T}(\mathrm{AG})$ retinoblastoma tumors. Invest Ophthalmol Vis Sci. 2011;52:5359-5368.

12. Boutrid H, Jockovich ME, Murray TG, et al. Targeting hypoxia, a novel treatment for advanced retinoblastoma. Invest Ophthalmol Vis Sci. 2008;49:2799-2805.

13. Boutrid H, Pina Y, Cebulla CM, et al. Increased hypoxia following vessel targeting in a murine model of retinoblastoma. Invest Ophthalmol Vis Sci. 2009;50:5537-5543.

14. Piña Y, Houston SK, Murray TG, et al. Focal, periocular delivery of 2-deoxy-D-glucose as an adjuvant to chemotherapy for the treatment of advanced retinoblastoma. Invest Ophthalmol Vis Sci. 2010;51(12): 6149-6156.

15. Lampidis TJ, Kurtoglu M, Maher JC, et al. Efficacy of 2-halogen substituted D-glucose analogs in blocking glycolysis and killing "hypoxic tumor cells". Cancer Chemother Pharmacol. 2006;58:725-734.

16. Maher JC, Krishan A, Lampidis TJ. Greater cell cycle inhibition and cytotoxicity induced by 2-deoxy-D-glucose in tumor cells treated under hypoxic vs aerobic conditions. Cancer Chemother Pharmacol. 2004;53: $116-122$.

17. Berman EL, Donaldson CE, Giblin M, Martin FJ. Outcomes in retinoblastoma, 1974-2005: the Children's Hospital, Westmead. Clin Experiment Ophthalmol. 2007;35:5-12.

18. Rouic LL, Aerts I, Levy-Gabriel C, et al. Conservative treatments of intraocular retinoblastoma. Ophthalmology. 2008;115(8): $1405-1410$.

19. Schefler AC, Cicciarelli N, Feuer W, Toledano S, Murray TG. Macular retinoblastoma: evaluation of tumor control, local complications, and visual outcomes for eyes treated with chemotherapy and repetitive foveal laser ablation. Ophthalmology. 2007;114:162-169.

20. Windle JJ, Albert DM, O'Brien JM, et al. Retinoblastoma in transgenic mice. Nature. 1990;343:665-669.

21. Jockovich ME, Pina Y, Alegret A, Cebulla C, Feuer W, Murray TG. Heterogeneous tumor vasculature in retinoblastoma: implications for vessel targeting therapy. Retina. 2008;28:S81-S86.

22. Piña Y, Boutrid H, Murray TG, et al. Ophthalmic vasculature alterations following systemic chemotherapy and periocular Carboplatin treatment of advanced retinoblastoma. J Pediatr Ophthalmol Strabismus. 2010;47: e1-e5.

23. Gentleman RC, Carey VJ, Bates DM, et al. Bioconductor: open software development for computational biology and bioinformatics. Genome Biol. 2004;5:R80.

24. Team RDC. R: A Language and Environment for Statistical Computing. Vienna, Austria: R Foundation for Statistical Computing; 2010.

25. Maschek G, Savaraj N, Priebe W, et al. 2-deoxy-D-glucose increases the efficacy of adriamycin and paclitaxel in human osteosarcoma and non-small cell lung cancers in vivo. Cancer Res. 2004;64:31-34.
26. Maher JC, Wangpaichitr M, Savaraj N, Kurtoglu M, Lampidis TJ. Hypoxia-inducible factor- 1 confers resistance to the glycolytic inhibitor 2-deoxy-D-glucose. Mol Cancer Ther. 2007;6:732-741.

27. Pina Y, Boutrid H, Schefler A, et al. Blood vessel maturation in retinoblastoma tumors: spatial distribution of neovessels and mature vessels and its impact on ocular treatment. Invest Ophthalmol Vis Sci. 2009;50:1020-1024

28. Sanchez-Elsner T, Botella LM, Velasco B, Corbi A, Attisano L, Bernabeu C. Synergistic cooperation between hypoxia and transforming growth factor-beta pathways on human vascular endothelial growth factor gene expression. J Biol Chem. 2001;276:38, 527-538.

29. Zhang H,Akman HO, Smith EL, Zhao J, Murphy-Ullrich JE, Batuman OA. Cellular response to hypoxia involves signaling via Smad proteins. Blood. 2003;101:2253-2260.

30. Akman HO, Zhang H, Siddiqui MA, Solomon W, Smith EL, Batuman OA. Response to hypoxia involves transforming growth factor-beta2 and Smad proteins in human endothelial cells. Blood. 2001;98: 3324-3331.

31. Kurtoglu M, Maher JC, Lampidis TJ. Differential toxic mechanisms of 2-deoxy-D-glucose versus 2-fluorodeoxy-D-glucose in hypoxic and normoxic tumor cells. Antioxid Redox Signal. 2007;9:1383-1390.

32. Kurtoglu M, Philips K, Liu H, Boise LH, Lampidis TJ. High endoplasmic reticulum activity renders multiple myeloma cells hypersensitive to mitochondrial inhibitors. Cancer Chemother Pharmacol. 66: 129-140.

33. Liu H, Hu YP, Savaraj N, Priebe W, Lampidis TJ. Hypersensitization of tumor cells to glycolytic inhibitors. Biochemistry. 2001;40: 5542-5547.

34. Liu H, Savaraj N, Priebe W, Lampidis TJ. Hypoxia increases tumor cell sensitivity to glycolytic inhibitors: a strategy for solid tumor therapy (Model C). Biochem Pharmacol. 2002;64:1745-1751.

35. Maher JC, Savaraj N, Priebe W, Liu H, Lampidis TJ. Differential sensitivity to 2-deoxy-D-glucose between two pancreatic cell lines correlates with GLUT-1 expression. Pancreas. 2005;30:e34-e39.

36. Bertout JA, Patel SA, Fryer BH, et al. Heterozygosity for hypoxia inducible factor 1alpha decreases the incidence of thymic lymphomas in a p53 mutant mouse model. Cancer Res. 2009;69: 3213-3220.

37. Miyazaki H, Watabe T, Kitamura T, Miyazono K. BMP signals inhibit proliferation and in vivo tumor growth of androgen-insensitive prostate carcinoma cells. Oncogene. 2004;23:9326-9335.

38. Lorente-Trigos A, Varnat F, Melotti A, Ruiz i Altaba A. BMP signaling promotes the growth of primary human colon carcinomas in vivo. $J \mathrm{Mol}$ Cell Biol. 2010;2:318-332.

39. Maschauer S, Prante O, Hoffmann M, Deichen JT, Kuwert T. Characterization of $18 \mathrm{~F}-\mathrm{FDG}$ uptake in human endothelial cells in vitro. J Nucl Med. 2004;45:455-460.

40. Loike JD, Cao L, Brett J, Ogawa S, Silverstein SC, Stern D. Hypoxia induces glucose transporter expression in endothelial cells. $\mathrm{Am}$ J Physiol. 1992;263:C326-C333.

41. Buck AK, Reske SN. Cellular origin and molecular mechanisms of $18 \mathrm{~F}-\mathrm{FDG}$ uptake: is there a contribution of the endothelium? $\mathrm{J} \mathrm{Nucl}$ Med. 2004;45:461-463.

42. Sone H, Deo BK, Kumagai AK. Enhancement of glucose transport by vascular endothelial growth factor in retinal endothelial cells. Invest Ophthalmol Vis Sci. 2000;41:1876-1884.

43. Merchan JR, Kovacs K, Railsback JW, et al. Antiangiogenic activity of 2-deoxy-D-glucose. PLoS One. 2010;5:e13699.

44. Carmeliet P. Angiogenesis in health and disease. Nat Med. 2003;9: 653-660.

45. Rafii S, Lyden D, Benezra R, Hattori K, Heissig B. Vascular and haematopoietic stem cells: novel targets for anti-angiogenesis therapy? Nat Rev Cancer. 2002;2:826-835.

46. Ziemssen F, Wegner R, Wegner J, et al. Analysis of neovasculature in uveal melanoma by targeting the TGFbeta-binding receptor endoglin: is there prognostic relevance of proliferating endothelium? Graefes Arch Clin Exp Ophthalmol. 2006;244:1124-1131. 
47. Folkman J. Seminars in Medicine of the Beth Israel Hospital, Boston. Clinical applications of research on angiogenesis. $N$ Engl J Med. 1995;333:1757-1763.

48. Rosenblatt MI, Azar DT. Anti-angiogenic therapy: Prospects for treatment of ocular tumors. Semin Ophthalmol. 2006;21:151-160.

49. Stitt AW, Gardiner TA. Anti-angiogenic therapy for uveal melanoma more haste, less speed. Br J Ophthalmol. 2002;86:368-369.

50. Yang H, Grossniklaus HE. Combined immunologic and anti-angiogenic therapy reduces hepatic micrometastases in a murine ocular melanoma model. Curr Eye Res. 2006;31:557-562.

51. Clark AF, Mellon J, Li XY, et al. Inhibition of intraocular tumor growth by topical application of the angiostatic steroid anecortave acetate. Invest Ophthalmol Vis Sci. 1999;40:2158-2162.

52. Bergers G, Benjamin LE. Tumorigenesis and the angiogenic switch. Nat Rev Cancer. 2003;3:401-410.

53. Bergers G, Song S, Meyer-Morse N, Bergsland E, Hanahan D. Benefits of targeting both pericytes and endothelial cells in the tumor vasculature with kinase inhibitors. J Clin Invest. 2003;111:1287-1295.

54. Jockovich ME, Bajenaru ML, Pina Y, et al. Retinoblastoma tumor vessel maturation impacts efficacy of vessel targeting in the $\mathrm{LH}_{\mathrm{BETA}} \mathrm{T}_{\mathrm{AG}}$ mouse model. Invest Ophthalmol Vis Sci. 2007;48:2476-2482.

55. Piña Y, Decatur C, Murray TG, et al. Advanced retinoblastoma treatment: targeting hypoxia by inhibition of the mammalian target of rapamycin (mTOR) in $\mathrm{LH}_{\mathrm{BETA}} \mathrm{T}_{\mathrm{AG}}$ retinal tumors. Clin Ophthalmol. 2011;5:337-343.

56. Creekmore AL, Walt KA, Schultz-Norton JR, et al. The role of retinoblastoma-associated proteins 46 and 48 in estrogen receptor alpha mediated gene expression. Mol Cell Endocrinol. 2008;291:79-86.

57. Gao G, Goff SP. Isolation of suppressor genes that restore retrovirus susceptibility to a virus-resistant cell line. Retrovirology. 2004;1:30.

58. Weihofen WA, Berger M, Chen H, Saenger W, Hinderlich S. Structures of human N-Acetylglucosamine kinase in two complexes with $\mathrm{N}$-Acetylglucosamine and with ADP/glucose: insights into substrate specificity and regulation. J Mol Biol. 2006;364:388-399.
59. Wolosker H, Kline D, Bian Y, et al. Molecularly cloned mammalian glucosamine-6-phosphate deaminase localizes to transporting epithelium and lacks oscillin activity. FASEB J. 1998;12:91-99.

60. Board M, Colquhoun A, Newsholme EA. High Km glucosephosphorylating (glucokinase) activities in a range of tumor cell lines and inhibition of rates of tumor growth by the specific enzyme inhibitor mannoheptulose. Cancer Res. 1995;55:3278-3285.

61. Wells L, Vosseller K, Hart GW. A role for N-acetylglucosamine as a nutrient sensor and mediator of insulin resistance. Cell Mol Life Sci. 2003;60:222-228.

62. Zachara NE, O'Donnell N, Cheung WD, Mercer JJ, Marth JD, Hart GW. Dynamic O-GlcNAc modification of nucleocytoplasmic proteins in response to stress. A survival response of mammalian cells. J Biol Chem. 2004;279:30133-30142.

63. Gianni D, Taulet N, DerMardirossian C, Bokoch GM. c-Src-mediated phosphorylation of NoxA1 and Tks4 induces the reactive oxygen species (ROS)-dependent formation of functional invadopodia in human colon cancer cells. Mol Biol Cell. 21:4287-4298.

64. Sousa MS, Latini FR, Monteiro HP, Cerutti JM. Arginase 2 and nitric oxide synthase: pathways associated with the pathogenesis of thyroid tumors. Free Radic Biol Med. 49:997-1007.

65. Dong X, Tang H, Hess KR, Abbruzzese JL, Li D. Glucose metabolism gene polymorphisms and clinical outcome in pancreatic cancer. Cancer. 2011;117(3):480-491.

66. Pina $\mathrm{Y}$, Boutrid $\mathrm{H}$, Murray TG, et al. Impact of tumor-associated macrophages in $\mathrm{LH}_{\mathrm{BETA}} \mathrm{T}_{\mathrm{AG}}$ Mice on retinal tumor progression: relation to macrophage subtype. Invest Ophthalmol Vis Sci. 2010;51: 2671-2677.

67. Houston SK, Pina Y, Clarke J, et al. Regional and temporal differences in gene expression of $\mathrm{LH}_{\mathrm{BETA}} \mathrm{T}_{\mathrm{AG}}$ retinoblastoma tumors. Invest Ophthalmol Vis Sci. 2011;52(8):5359-5368.
Clinical Ophthalmology

\section{Publish your work in this journal}

Clinical Ophthalmology is an international, peer-reviewed journal covering all subspecialties within ophthalmology. Key topics include: Optometry; Visual science; Pharmacology and drug therapy in eye diseases; Basic Sciences; Primary and Secondary eye care; Patient Safety and Quality of Care Improvements. This journal is indexed on Submit your manuscript here: http://www.dovepress.com/clinical-ophthalmology-journal

\section{Dovepress}

PubMed Central and CAS, and is the official journal of The Society of Clinical Ophthalmology (SCO). The manuscript management system is completely online and includes a very quick and fair peer-review system, which is all easy to use. Visit http://www.dovepress.com/ testimonials.php to read real quotes from published authors. 